\title{
Methods and Approaches of Teaching English: a Historical Review
}

Omar A. Albukbak ${ }^{1}$

Amel M. Msimeer

Faculty of Arts, Misurata University

Received: 17-04- 2021 Accepted: 29-06- 2021 Available Online: 30 -06- 2021

https://doi.org/10.36602/faj/2021.n17.14

\begin{abstract}
It might be quite difficult to say that one teaching method or approach is the best to be adopted in English classes. A little knowledge of the history of these methods and approaches can lead to unsuccessful application inside language classrooms. Therefore this methodological research paper presents a historical background of some teaching methods and approaches which have been used in language education throughout history of teaching/learning English. It introduces the principles on which each teaching method and approach is based. Furthermore, it provides details about the advantages and disadvantages of each method and approach besides their limitations. The paper deals with only five methods and approaches of teaching English because of the limited number of pages determined by the journal. Namely they are: Grammar Translation Method, Direct Method, Oral Approach and Situational Language Teaching, AudioLingual Method, and Communicative Language Teaching. Finally, the paper ends with a conclusion showing the result of its research and intended work to be done in the near future.
\end{abstract}

Key words: Grammar Translation Method, Direct Method, AudioLingual Method, Oral Approach and Situational Language Teaching, Communicative Language Teaching.

O.albukbak@art.misuratau.edu.ly ${ }^{1}$ 


\section{طرق وأساليب في تدريس اللغة الإنجليزية: مراجعة تاريخية

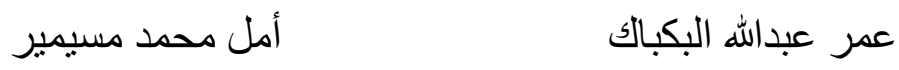 كلية الآداب - جامعة مصر اتة}

\section{ملخص البحث}

قد يكون من الصعب الجزم بأن طريقة محددة أو أسلوب تدريس معين يكون هو أفضل ما يمكن إتباعه داخل فصول تدريس اللغة الإنجليزية. أيضاً المعرفة القليلة بتاريخ هذه الطرق و الأساليب قد يؤدي إلى تطبيقها بطريقة غير ناجحة. لهذا فإن هذه الورقة البحثية تطرح خلفية تاريخية حول بعض الطرق و أساليب التدريس التي استخدمت في تدريس اللغة الإنجليزية عبر التاريخ. إن هذه الورقة البحثية تستعرض المبادئ و الأسس التي تقوم عليها كل طريقة أو أسلوب تدريس، كذلك هي تستعرض المميزات والعيوب وأوجه القصور لكل منها. هذه الدراسة سوف تتناول فقط خمسة أنواع من طرق و أساليب تدريس اللغة الإنجليزية وذلك بسبب العدد المحدود لصفحات البحث طبقا لمواصفات المجلة. والطرق والأساليب هي: طريقة الترجمة النحوية، والطريقة المباشرة، والنهج الشفهي وتعليم اللغة الظرفية، والطريقة الصوتية اللغوية، وتعلم اللغة التواصلي. أخيرا تنتهي الورقة البحثية بخاتمة توضح نتيجة البحث والعمل المزمع القيام به في المستقبل القريب.

الكلمات الأساسية: طريقة الترجمة النحوية، الطريقة المباشرة، الطريقة الصوتية واللغوية، النهج الشفهي وتعليم اللغة الظرفية، تعليم اللغة التواصلي. 


\section{Introduction}

It is well-known that language teachers in any learning/teaching context frequently encounter difficulties about which teaching method or approach is more appropriate to utilize when teaching English as a foreign language (EFL) or as a second language (ESL) in classrooms. Also, they might misunderstand the differences between the principles on which they are based on and how to use them. In reply to all these enquiries, this paper reviews the historical research in which it attempts to shed light on the appearance of these teaching methods and approaches and their development.

Starting by defining the two terms: method and approach, Antony (cited in Celce-Murcia, Brinton and Snow,2014) described a method as, "a set of procedures" while an approach is a reflection of "a theoretical model or research paradigm" (p.2). Another definition of these two is provided by Richard and Rogers (2001) who determined that a teaching method is "a specific instructional design or system based on a particular theory of language and language learning" while a teaching approach is considered as "a set of beliefs and principles that can be used as the basis for teaching a language" (pp. 244-245). Gill and Kusum (2016) in this sense explain that approach is a broader term than method and that an approach may have many methods. Furthermore, Richard and Rogers (2001) illustrate that a teaching method provides detailed terms of content, teachers and learners' role and teaching procedures and techniques and it is quite predetermined in time. On the contrary, a teaching approach is characterized by a wide variety of applications and has a long shelf life. It can be revised and modified as new practices evolve over time.

\subsection{The Significance of the Study}

The deep knowledge of any branch of science needs a profound knowledge of its history, philosophy, and pros and cons. So language teachers should have a insightful knowledge about different language methods and approaches in teaching English as a foreign language. In 
this regard, it is highly significant to show the reasons behind studying these methods and approaches in their past experience, present effect and future influence. According to Richards and Rogers (2001), teachers and students had better know major teaching methods and approaches so that they become familiar with different debates and issues related to the history of language teaching. In addition, they will be aware of the way in which theory and practice can be connected in a number of different views. They add that having such knowledge will assist teachers use different methods and approaches and decide when it is appropriate to use them.

\subsection{Research Questions}

1. What are the principles, advantages and disadvantages, and limitations of methods and approaches of teaching English?

2. Does teachers' profound knowledge of the teaching methods and approaches influence their successful implication inside classrooms?

\section{Literature Review}

\subsection{Grammar Translation Method}

The Grammar Translation Method (GTM) has been used by language teachers for many centuries. Richards \& Schmidt (2002) point out that it is a method of second language (L2) teaching which considers translation and grammar study as the central activities in the process of teaching and learning. In Europe, Latin and Greek were traditionally taught according to this way. In the $19^{\text {th }}$ century it began to be used to teach modern languages such as German, French and English. The presentation of a grammatical rule, a study of lists of vocabulary and a translation exercises construct its typical lesson.

Little (2006) states that 'The Grammar-Translation method sees language learning as a matter of consciously mastering the grammatical system of the target language (TL). It uses translation between the learner's mother tongue and the TL as the chief means of 
analyzing, practicing and learning grammar, and of learning the vocabulary without which grammar is useless'. The use of the GTM made learners become adept in the use of correct grammar in writing. They received enough training in translating texts from their native language to the target language.

Johnson \& Johnson (2009) argue that this method is for classes where language learners are monolingual, and it focuses on the written language. It introduces language under instruction through explicit sentences of rules in the students' first language (L1), then practicing and testing these rules through sentence translation. They add that it has continued to be used in many parts of the world; it is one of the few methods that it is possible to employ in very large classes. What is more, this method is appropriate for teachers whose mastery of L2 might be limited. The GTM teachers must know both the target language and the students' L1. Such teachers have the advantage of being familiar with their learners' language specific problems.

The goal of the method is to learn language in order to benefit from its literature and the mental discipline provided in foreign texts. As such, it requires proficiency in translation from the target to the native language and vice versa. Using the native language as the medium of instruction, it provides comprehensive training in translating sentences with high-level accuracy. Its main focus is to attain mastery in reading and writing, hence placing very little emphasis on listening and speaking. This implied mastery of grammar rules, yet an inability to apply them in verbal utterances. The teacher uses the deductive method of instruction, which requires laying down grammar rules then applying such rules to translation exercises. As such, this makes students become dependent on grammar rules introduced in class, and compromises their ability to express themselves when confronted with challenges in real-life settings. The limited exercises and exposure to texts due to translation also hampers vocabulary acquisition, thus defeating the main purpose of allowing learners to explore foreign materials (Johnson \& Jonson,2009).

https://misuratau.edu.ly/journal/arts 
The advantages and disadvantages of the GTM as far as the benefit of the majority is concerned. On the one hand, the method allows translation of many texts, which cultivates a means for transformation in European civilization; to date, translation is still used as an effective means of communicating ideas from one culture to another. On the other hand, translation skills are limited to the learned, making it a privilege for those who are able to afford education in private institutions or language schools. In this view, the common people are deprived of foreign language faculty, and only those who are schooled and took great interest in reading and writing could understand translated texts. The use of the foreign language for trade and international affairs was very rare compared to the present situation. It should also be emphasized that the GTM brings about disinterest in many foreign language learners, who grow weary of memorizing long lists of vocabulary and grammar rules for the sake of accurate translation.

According to Al-Mutawa \& Kailani (2003), there are limitations underlying the GTM. Firstly, it aims to impart knowledge of the grammar of the language, which gives the rules for constructing words together, and the focus is on form and inflection. Second, it does not set out rules enabling the learner to construct systematically correct complex sentences, and students are often trained in artificial forms of language when practicing the rules. It also takes little account of present-day language usage and emphasizes the written language at the expense of the oral language and of how it is used to convey social functions. The focus is on knowing rules and exceptions while communicative skills are ignored. Besides, students practice reading in order to memorize a number of vocabulary items and for translation. In teaching vocabulary, separate words are taught in the form of lists. Teaching is done mostly in the L1, and the over-use of the $\mathrm{L} 1$ reduces the time available for practice in the TL. Moreover, the technique of giving definitions, rules and explanations makes the process of teaching boring and is of little benefit to the students. Finally, the students' role is largely passive and they learn more about 
how the language works than about how to use the language communicatively (Al-Mutawa \& Kailani,2003).

\subsection{Direct Method}

In response to the problems brought about by the GTM, proponents who believed in the natural method of language learning and acquisition resorted to the Direct Method (DM) to facilitate learning a foreign language. The DM is one of the "natural methods". The term "natural method", according to Richards and Schmidt 2002, implies that a method emphasizes the use of spoken language, objects and actions in teaching word meanings and structure, and following the natural beliefs of first language learning. Sauveur and other followers of natural methods (cited in Richards \& Rodgers 2001) proposed the idea that a foreign language can be learned best by demonstration and not by translation. The DM thus made exclusive use of the target language for instruction, and dispensed with translations. Unlike the former GTM, which focused on writing, the DM emphasized speaking and inductive teaching methods. These methods emphasize using the language instead of presenting information about the language. Furthermore, learners are not taught grammatical rules directly but they discover these rules from their experience of using the language. In other words, learners inferred grammar rules from sentence samples.

To promote learning, teachers employed miming, photos and demonstration during practice speaking exercises. Strict rules were applied, prohibiting the use of the first language, translating, speaking aloud, using books for references, and manipulating discussion. Conversely, it promoted the sole use of the target language, comprehension through demonstration, speaking naturally, using lesson plans, and giving more chances for students to speak. Among its strengths were student-centered instruction, natural and everyday speaking situations, creative use of demonstration and photos, and emphasis on pronunciation.

https://misuratau.edu.ly/journal/arts 
Larsen-Freeman (2000) points out that teachers who use the DM propose that students learn to speak the TL by learning to think in the TL. The syllabus of DM is based on situations (for example, one unit would focus on the language used at a bank, while another might focus on the language used at a shop) or topics (such as geography, weather, or money). She adds that an explicit grammar rule may never be given; instead students are presented with examples then they figure out the rule from the examples. The students study culture consisting of the history of the native speakers of the TL, the geography of the country of the TL, and information about the daily routine of the native speakers' lives. According to Al-Mutawa \& Kailani (2003), the theory was derived from the hypothesis that learning a FL is very similar to learning one's first language, i.e. "that exposing the language impresses it perfectly upon the learner's mind".

Al-Mutawa \& Kailani (2003) describe the DM that it gives priority to speech and oral skills, and discards memorization of conjugations, declensions and rules of grammar. Simultaneously, it discards the learners' first language because it regards translation a worthless activity in language teaching; therefore the meaning of concrete or abstract words and sentences is given through dramatization, demonstration or pointing at objects without using the L1. In order to teach words and patterns, it must be done through direct association with actions, dialogues, situations, objects or pictures. After imitation, students memorize selected FL sentences, short dialogues, expressions and songs. Reading and writing are delayed for months and pronunciation is emphasized. However, they add, exercises have failed to achieve decisive results or authentic learning on the part of the student because all language activities are related to the classroom and not connected with real life situations. In other words, they do not prepare learners for using the FL for communication, and the teachers do not think of students using the language outside the classroom. In addition, this method has been criticized for its time-consuming and roundabout techniques of giving the meaning of words and structures through dramatization, 
demonstration or association without resorting to the L1. Moreover, the method necessitates an extremely proficient teacher who is gifted with fluency in the foreign language (FL) and in-depth understanding of its techniques. It also calls for a large number of class hours as the majority of the work is done in the classroom.

On the one hand, the DM found success in implementation among private language schools. The help of the foreign teacher in teaching students who were willing and able to pay made an impact on language learners. On contrary, there was a resistance in the public sector, with the severe use of the foreign language, which undermined comprehension. Failure to realize practical learning was also evident, with the limited skills of the (FL) teacher, who unexpectedly became the focus of instruction, especially in situations where learners lacked the ability to use the language. Problems were also met with finding teachers who can teach using the DM approach, due to restrictions in the use of the target language.

Richards \& Rodgers (2001) state that by the 1920s, the drawbacks caused by the Direct Method were further realized, especially by linguists who later proposed the combination of the Direct Method and grammar-based activities. Such a combination resulted in reading-centered instruction to address comprehension issues. This subsequently led reformers to focus on the need to develop comprehension not only through reading but also through listening and gaining understanding of communication situations, the goals of Oral and Situational Language Teaching.

\subsection{Oral Approach and Situational Language Teaching}

The 1920 s to 1930 s saw further transformation in the field of language teaching with the Oral Approach proposed by Harold Palmer and A.S. Hornby, two British linguists who formulated that reading and vocabulary are important aspects of teaching a foreign language (Richards \& Rodgers 2001). With its heightened concern for reading skills, the Oral Approach reflects largely the trends following the DM. 
The approach took into consideration content and structure. Thus, its syllabus included a listing of vocabulary words and grammar content taught at designated levels of language learning. The approach employed inductive teaching method; thus students were made to realize structure by providing numerous samples of sentences designed to be recited orally. Like the DM, the approach made exclusive use of the target language, and aided oral recitation of sentences with the use of demonstration and communication situations. Explanation of terms was discouraged; thus students inductively deduced the meaning of vocabulary words based on a given context.

By the 1950s, the Oral Approach was widely accepted as the British approach to English language teaching (Richards \& Rodgers 2001). It was widely adopted by many schools and teachers, including the Australian George Pittman, who developed teaching materials applying the approach to specific situations. The emphasis on situations later led to the coinage of the term Situational Language Teaching (SLT). With the use of situations, students gained both knowledge of structures, and skills based on the way language was applied in different situations.

The approach relied strongly on structural and behavioral theories. Its proponents believed that teaching students the structure of the language was fundamental to learning. Teachers paid particular attention to developing speaking skills before other language skills. Therefore, drills were recited first before presenting them in written form. The teacher acted as the model while students imitated the teacher during oral exercises.

Situations were used to aid in comprehending new language materials. They were controlled by the teacher to limit the demonstration and practice within target concepts. Unlike the GTM that required explanation of grammatical structure/patterns, SLT made use of demonstrations using real objects, pictures, action, and mime to help learners comprehend new vocabulary. The sequence of activities consisted therefore of listening practice, choral imitation, 
individual imitation, isolation of sounds, inductive construction of sentence patterns, eliciting sentences and questions, substitutiondrilling, question and answer drilling, and correction of errors. Notably, teachers used a friendly approach in correcting errors by shaking their heads when students gave wrong answers. They also allowed learners to correct each other by making them listen to one another (Richards \& Rodgers, 2001).

With its practical use of illustrations and sentence patterns, SLT became the basis of many approaches that followed. Many authors also adopted the concept of structuralism for textbook exercises and sentence samples for foreign language dictionaries. However, some of the drawbacks of SLT which included imitative oral skills and controlled means as expression led successors to revise the approach further, thus giving way to the Audio-lingual Method.

\subsection{Audio-Lingual Method elaborate}

Johnson \& Johnson (2009) state, "In the Second World War the Americans discovered the need for mastery of foreign languages by service personnel" (p20). Assistance was sought from structural linguists_who eventually elaborated the mimicry-memoriztion method to be used as a hurried pragmatic measure in the context of the Army Specialized Training Program.

According to Richards \& Schmidt (2002), this method is also called aural-oral. It emphasizes the teaching of speaking and listening before reading and writing and uses dialogues and drills in teaching these skills. It discourages the use of the L1 in the classroom. The Audio-lingual method is based on the aural-oral approach theory of language teaching. This theory holds the following beliefs about language: (a) speaking and listening are the mainly vital skills in language learning, (b) each language possess its unique structure and rule system, and (c) a language is learned through habit formation. Little (2006) points out that the Audio-lingual method is originated from the learning theories of behaviorist psychology. It sees language 
learning as a matter of conditioning and habit formation. The learner is drilled in structural patterns and their variations by means of stimulus-response-reinforcement exercises.

Similar to SLT, the Audio-lingual method focused on enhancing speaking skills. As such, speech drills were led by the teacher as the model. However, unlike SLT, which promoted knowledge of sentence structures and grammatical rules, the Audio-lingual method did not emphasize the need to gain systematic understanding of language content and structure. Also, while the SLT used pictures and visual demonstrations, the Audio-lingual method made use of recorded materials with sample utterances, which students mimicked, and which helped students increase their understanding of speech rules and patterns.

Concerning the aim of this method, Johnson \& Johnson (2009) point out that it seeks to teach listening, speaking, reading, and writing, in that order, with concentration on the language used in everyday situations in the early years. Language learning is based on use of dialogues that include frequent items of everyday vocabulary and structure. Dialogues are learnt by mimicry-memorization, with special emphasis is placed on pronunciation and intonation. When the entire class has perfected the dialogues, they are divided, and dialogues are performed as if they were 'real-life' ones, with questions and answers exchanged between divisions and role reversal. The structures of dialogues are strengthened and developed by pattern drill, done first in groups and subsequently individually, or in the language laboratory.

Later, learners are introduced to written texts, though writing is at first imitative and consists of copying exercises. Cook (2001), meanwhile, argues that Audio-lingual teaching not only accepts that language is divided into the four skills of listening, speaking, reading and writing but takes it further by dividing the skills into active and passive skills. Active skills refer to those which people use to produce a language i.e speaking and writing skills, while passive skills are those in which people receive a language i.e listening and reading. 
Passive skills should come before active skills. For example speech comes before writing. So students should lean to listen before they learn to speak, speak before they learn to read, and read before they learn to write. Needless to say, hardly one now accepts that listening is 'passive'.

Hapudin (2015, p. 29) argues that teachers "believe students need to over learn the TL, to learn to use it automatically without stopping to think. Their students achieve this by forming new habits in the TL and overcoming the old habits of their native language". Larsen-Freeman (2000) adds that teachers who use the Audio-Lingual method:

Drills (such as repetition, backward build-up, chain, substitution, transformation, and question-and-answer) are conducted, based upon the patterns present in the dialogue. Students' successful responses are positively reinforced. Grammar is induced from the examples given; explicit grammar rules are not provided (p.45).

She states that the nature of the activities in the Audio-lingual method suggests that oral drills are a typical part of those activities. It requires the sounds or pronunciation of words or sentences to be modeled by the teacher, while students repeat the utterances. The medium of instruction is the target language. Although translation is allowed, it is discouraged. The main purpose is to gain mastery of the verbal language; hence grammatical structure is set aside. Like SLT, the approach also employs substitution. The teacher, after uttering the sentence, removes some words to be replaced by the students.

In the relationship between speaking and writing, Cook (2001) states that the Audio-lingual style interprets the assumption that speech should take precedence over writing in two ways. One is shortterm: whatever the students learn must be heard before it is being seen, so the teacher must say the new words aloud before writing them on the blackboard. The other is long-term: the students here must spend time developing their oral skills before they are being introduced to the written skills; this might take a few week or perhaps 
a year. This long-term interpretation brings about some about problems in that adult students who use the written text as a support would not accept it being taken away from them and therefore they might try to find an alternative way to get it back, like writing down the text under their desk. lead

Typically, an Audio-lingual lesson is composed of (1) listening to a model conversation, (2) acting out of the dialogue by the students, (3) selection of key structures of the dialogues for use in drills both individual and chorus, (4) reading/writing/vocabulary exercises based on the model dialogue, and (5) enrichment activities. The success of the Audio-lingual method declined after the 60s as opposition arose regarding the learning theory behind the approach. Also, the failure of the approach to prepare learners with the capability to apply classroom learning to real-life communication was noted. Nevertheless, successive approaches retained the use of Audio-lingual resources to further promote language learning (Cook 2001).

Johnson \& Johnson (2009) explain, "The theoretical claims for Audiolingualism were ... demolished, indirectly, in the work of Chomsky, not least by his insistence that language cannot be regarded as a repertoire and that its acquisition is not a mechanistic process." (p.22).

Accordingly, Finocchiaro \& Brumfit (2003) claim that learners were often prevented from saying what they wanted to say because of the 'rules' of the theory. Audio-lingual theory, as presented to teachers, was very strong on what students ought not to do: they should not write down versions of what they heard, they should not attempt to use linguistic forms they had not been drilled in, they should not learn words out of context. While it is true that the spoken language was given priority and that the film strips and/or films provided students insight into both linguistic features and paralinguistic features of communication, too more importance was often placed on mechanical repetition of the tape and the objective was generally having command of sentence pattern rather than 
creative or real communicative use of language (Finocchiaro \& Brumfit,2003).

Al-Mutawa \& Kailani (2003) point out some criticisms of this approach. First, it asserts speech over other skills, particularly writing, and the ordering of listening, speaking, reading, and writing is not important because there is no basic reason why all language skills cannot be taught simultaneously. Secondly, it takes no account of the creative use of language and cognition. Empirical evidence has also shown that pattern practice, though useful for the early stages of FL learning, is not conducive to real communication. Thirdly, it is based on the misleading notion that acquisition of the rules of the TL is connected with the ability to communicate effectively in it, because learning to produce grammatical sentences does not guarantee that one will be able to communicate in situations that require the creative use of speech acts such as requesting, disagreeing, expressing opinions, showing feelings of sympathy, etc. Finally, it requires small classes, carefully prepared materials and a lot of time, and a well-trained teacher who knows 'what to teach' and 'how to teach' adequately.

\subsection{Communicative Language Teaching}

The constant need to find appropriate approaches to facilitate learning and instruction prompts the use of an innovative approach that addresses current problems and issues in education. Innovation allows improved learning conditions for both students and teachers, making it imperative for educators to constantly review approaches and strategies they employ.

In the area of second and foreign language teaching, the birth of a new approach usually relies on previously used approaches, which are altered to improve effectiveness and remedy learning difficulties. Hence, the origins of Communicative Language Teaching (CLT) can be traced back to other approaches made popular in the early 1900s.

The communicative classroom is fundamentally different in many ways to a grammar-focused or audio-lingual classroom. In the 
communicative classroom, learners are given opportunities to express themselves orally using the target language. Unlike in the grammarfocused classroom, a communicative classroom discourages the use of the native language. However, unlike the audio-lingual classroom that strictly prohibits the use of the native language, the communicative classroom may rely on it for reference when necessary for example, students encounter a totally unfamiliar word and translating it to the native tongue is the only way to make them understood.

In addition, a communicative classroom encourages student interaction and an active learning environment. To achieve this, the teacher takes the role of a facilitator rather than the source of learning. Student-centered instruction is thus preferred over teacher-centered instruction. In this classroom, students do more of the talking and performance while the teacher observes and facilitates activities. Error correction, which may include a grammar lesson, comes at the end of the activity, and is relayed in a friendly and considerate manner. As much as possible, errors are not identified with students who committed them but are discussed objectively. Also, taking into consideration student-centered instruction, the teacher guides the students to correct the errors committed.

Bowen (2009) adds that a communicative classroom is different in terms of the organization of the lesson. The traditional classroom takes the 'present, practice and perform' model. In this model, students typically follow a particular structure of controlled, less controlled and freer practice. The communicative classroom, on the other hand, promotes a more task-based approach, taking the 'test, teach, test' structure. Here the learners perform a communicative task monitored by the teacher. This stage allows the students to apply previous learning. Then, the teacher guides students in fine-tuning their performance. This stage includes error correction and clarification. Finally, students perform a further task, requiring a greater degree of linguistic accuracy compared to the first performance.

https://misuratau.edu.ly/journal/arts 
Brown (2008) suggests specific practices for use in the CLT classroom. These include a significant amount of pair work and group work, use of real-life communication situations for authentic exercises, and encouraging students to produce genuine and meaningful language for communication. Additionally, Nunan (2004) stresses the use of materials which promote authentic and communicative language use. In this view, the CLT classroom often makes use of pair and group work. This ensures more cooperation and interaction among learners, which further develops students' confidence. It also develops students' knowledge of language functions, pronunciation, cues needed to express themselves with clarity.

Examples of CLT classroom activities include: role play, information gap exercise, interview, survey, panel discussion, oral presentation, learning by teaching, and games. However, this does not mean omitting grammar exercises. Activities should vary and include occasional grammar quizzes, non-communicative drills, or other individual exercises (Nunan, 2004).

Within CLT, authentic materials represent one component of any learning that enhances communication (Todd 2005). Todd adds that proponents of the CLT approach believe that authentic materials provide more exposure to the TL, which leads students to immerse themselves in the TL and consequently use it in actual communicative situations in real life contexts. The authentic materials, whatever the resources used are, present varieties of natural learning that provide more exposure to English and give more opportunities for real communication. In addition, Littlewood (2008) argues that using the TL provides a rich source for communicative needs in FL classrooms. Another component is giving instructions in the TL, which could be a good model of teachers' authentic language use in classrooms. Todd states: "The giving of instructions in the classroom is one of the few genuinely communicative acts which takes place and is thus a valuable opportunity for the teacher to exploit as authentic communication in the L2" (2005 p37). 
In communicative classrooms, according to Cook (2001), the teacher is no longer a dominant, controller or a guide of the students all time. Rather, the teacher takes a step back and delegate responsibility for the activities to the students, forcing them to create their own dialogues in pairs and groups - language learning by practice.

Little (2006) adds that communicative textbooks are organized around communicative functions, like greeting and leave-taking, or around communicative tasks, such as ordering a meal in a restaurant or making a hotel reservation. In part, communicative textbooks, like audio-lingual textbooks, have the status of scripts, but the communicative approach is methodologically eclectic (which is why it is called an 'approach' and not a 'method'), so that many communicative textbooks also contain grammatical paradigms and writing activities designed to facilitate learning by various kinds of analytic procedure.

\section{3- Conclusion}

This study is set to introduce a historical review of some teaching methods and approaches and their development through time. It provides language teachers with profound knowledge of the principles on which each of the above stated teaching methods and approaches is based on. Also, it presents the advantages and disadvantages of them besides the limitation of each one. The current study deals only with five teaching methods and approaches: Grammar Translation Method, Direct Method, Oral Approach and Situational Language teaching, Audio-Lingual Method, and Communicative Language Teaching.

Also, the current study reaches the result that there is no specific perfect teaching method or approach to be applied for English language teaching, instead it provides language teachers with information and details on the principles and ways of how to apply each method and approach and when to apply it, so they can select 
what is more appropriate for their learning contexts and learners' characteristics.

As the journal's regulations set a limited number of pages, it is intended to continue reviewing the rest of the methods and approaches of teaching English in a following research paper.

\section{References}

Al-Mutawa, N. and Kailani, T. (2003). Methods of Teaching English to Arab Students. $2^{\text {nd }}$ ed. UK: Longman Group Ltd.

Brown, H. D. (2008). Principles of language learning and teaching. $3^{\text {rd }}$ ed. Englewood Cliffs NJ: Prentice Hall.

Bowen, T.(2009). Teaching Approaches: The Communicative Classroom. [online]. Available from: $<$ http://www.onestopenglish.com/section.asp?docid=146489>

Celce-Murcia, M. et. al. (2014). Teaching English as a Second or Foreign Language. $4^{\text {th }}$ ed. Boston: National Geographic Learning.

Cook, V. (2001). L2 Learning and Language Teaching. $3^{\text {rd }}$ ed. London: Arnold.

Finocchiaro, M. and Brumfit, C. (2003). The Functional-Notional Approach: From Theory to Practice. $3^{\text {rd }}$ ed. Oxford: Oxford University Press.

Gill,A. K.\& Kusum,D. (2016). Teaching Approaches, Methods and Strategy. Scholarly Research Journal for Interdisciplinary Studies. Vol.4 issue 36. Pp6692- 6697

Hapudin, P. (2015). Reading Aloud: The Comparative Analysis of Teachers' Creativities in Teaching English Text at SMPN1Taluna and SMP Al-Hikmah, Published thesis. Syekh Nurjati State Islamic Institute Cirebon. 
Johnson, K. and Johnson, H. (2009). Encyclopedic Dictionary of Applied Linguistics. $6^{\text {th }}$ ed. UK: Blackwell Publishers Ltd.

Larsen-Freeman, D. (2000). Techniques and Principles in Language Teaching. 2nd ed. Oxford: Oxford University Press.

Little, D. (2006). Technologies, Media \& Foreign Language Learning. $3^{\text {rd }}$ ed. Dublin: Authentik Language Learning Resources Ltd.

Littlewood, W. (2008). Communicative Language Teaching. $4^{\text {th }}$ ed. Cambridge: Cambridge University Press.

Nunan, D. (2004). Designing Tasks for the Communicative Classroom. $3^{\text {rd }}$ ed. Cambridge: Cambridge University Press.

Richards, J. and Rodgers, T. (2001). Approaches and Methods in Language Teaching. Cambridge: Cambridge University Press.

Richards, J. C. and Schmidt, R. (2002). Longman Dictionary of Language Teaching \& Applied Linguistics. $3^{\text {rd }}$ ed. London: Person Education Limited.

Todd, R. W. (2005). Classroom Teaching Strategies. $4^{\text {th }}$ ed. London: Prentice Hall. 